\title{
Article
}

\section{The role of psychological characteristics in facilitating the pathway to elite performance. Part 2: Examining environmental and stage-related differences in skills and behaviors}

MacNamara, Á., Button, A., and Collins, D.

Available at http://clok.uclan.ac.uk/9250/

MacNamara, Á. ORCID: 0000-0002-8110-6784, Button, A., and Collins, D. ORCID: 0000-0002-7601-0454 (2010) The role of psychological characteristics in facilitating the pathway to elite performance. Part 2: Examining

environmental and stage-related differences in skills and behaviors. The Sport Psychologist, 24 (1). pp. 74-96. ISSN 0888-4781

It is advisable to refer to the publisher's version if you intend to cite from the work.

For more information about UCLan's research in this area go to

http://www.uclan.ac.uk/researchgroups/ and search for <name of research Group>.

For information about Research generally at UCLan please go to http://www.uclan.ac.uk/research/

All outputs in CLoK are protected by Intellectual Property Rights law, including Copyright law. Copyright, IPR and Moral Rights for the works on this site are retained by the individual authors and/or other copyright owners. Terms and conditions for use of this material are defined in the policies page. 


\title{
The Role of Psychological Characteristics in Facilitating the Pathway to Elite Performance Part 2: Examining Environmental and Stage-Related Differences in Skills and Behaviors
}

\author{
Áine MacNamara \\ University of Limerick \\ Angela Button \\ University of Otago \\ Dave Collins \\ P2E Consulting
}

\begin{abstract}
MacNamara, Button, \& Collins (under review) proposed that if individuals are to fulfill their potential they must possess and systematically develop a specific set of skills (termed Psychological Characteristics of Developing Excellence or PCDEs) that allow them to interact effectively with the developmental opportunities they are afforded. Given the complexity of the developmental pathway, it may well be that different skills are needed at different stages of development and across different performance domains. Twenty-four elite participants from team sports, individual sports, and music were purposefully sampled from different domains and interviewed on their experiences of their own pathways to excellence. Results suggested that although PCDEs were important throughout development, the manner by which they were deployed depended on stage, domain, and the characteristics of the individual performer. These findings support proposals to systematically incorporate PCDEs into TID practices because these may be the key feature in maintaining progress toward excellence.
\end{abstract}

Building on the role played by psychological characteristics as determinants of performance (Gould, Diffenbach, \& Moffett, 2002; Orlick \& Partington, 1998; Williams \& Krane, 2001), the retrospective study reported by MacNamara, Button,

MacNamara is with the Dept. of Physical Education and Sport Science, University of Limerick, Ireland. Button is with the University of Otago, Dunedin, New Zealand. Collins is with P2E Consulting, United Kingdom. 
and Collins (2010) stressed the importance of a range of psychological skills as critical determinants of development (i.e., commitment, imagery, coping skills). Termed "Psychological Characteristics of Developing Excellence", or PCDEs, these factors allowed aspiring elites to optimize development opportunities (e.g., first time appearances at a new level of competition, significant wins and losses), adapt to setbacks (e.g., injury, slumps in performance) and effectively negotiate key transitions (e.g., selection, demands for increased practice) encountered along the pathway to excellence. Accordingly, we proposed that if individuals are to fulfill their potentials they must possess and systematically develop the necessary PCDEs that allow them to interact effectively with the developmental opportunities they are afforded (Côté, 1999; Simonton, 1999).

However, it may well be that different skills are required at different stages, for different activities, or even idiosyncratically for different individuals. This understanding is especially significant given the complex 'pathways to excellence' that emerged from the athletes' retrospectives in MacNamara et al.'s study (2010). Aspiring elites will encounter not only macro stages of development (cf. Côté, 1999) but also less predictable micro stages and transitions of development (e.g., injury, change of performance environment). Ollis and colleagues provided evidence of these nonlinear, 'wave-like' pathways in their exploration of the careers of elite rugby referees (Ollis, Macpherson, \& Collins, 2006), a finding which fitted well with the nonlinear nature of the pathway suggested by Abbott, Button, Pepping, and Collins (2005). Each pathway in the Ollis et al. study was distinct, with no two participants following identical routes toward excellence. Instead, the manner by which individuals interpreted distinct incidents or more chronic experiences as facilitators and debilitators (a process itself dependant on psychological skills and characteristics) influenced the trajectory of their developmental pathway (Ollis et al., 2006). For example, the same incident (e.g., a poor performance at a high-level match) was interpreted as a positive growth experience for some of the referees, while others viewed it in a much more negative light. Given these individual variations in one single, very structured environment (i.e., the development of rugby referees), it seems likely that different approaches are needed at different stages across the longer and inherently more varied pathway to excellence experienced by young performers.

For example, the deployment of PCDEs may be complicated by the specific demands faced by participants within different performance domains. Early success in track and field athletics (e.g., sprinting), for instance, may be achieved with comparatively little effort (or even deliberate practice) if the athlete possesses natural ability, relatively greater physical maturity, and/or an appropriate physique. In contrast, the same early success is less likely to be evident in more technical sports (e.g., hockey) if the athlete hasn't yet developed the necessary technical and tactical skills to engage successfully. As an even more extreme case, young musicians must engage in highly technical and demanding practice before they can even begin to perform; a situation more akin to the most technical, artistic sports such as figure skating and gymnastics as well as pursuits such as ballet. In short, given that different performance environments require different levels of deliberate practice at different stages of development (Ericson, 1996), it may well be that there are activity related differences in the set of PCDEs required.

Moreover, the blend of psycho-behavioral factors may even change over time as athletes develop and their situations change. Simonton (1999) proposed that the 
factors composing a given talent interact and change as a function of time. Thus, the application of PCDEs may vary considerably along each individual's developmental trajectory. Simply, even though it is important to encourage young performers to engage in these 'champion behaviors' (Abbott et al., 2007), it is essential to consider how the context (e.g., performance domain) and characteristics (e.g., age, level of cognitive maturity) of the individual impacts on the differential deployment of these psychological behaviors. For example, although commitment was shown to be a key determinant of development in MacNamara et al.'s study (under review), commitment behaviors should vary depending on the context in which the individual is performing. Thus, while a committed elite sprinter might train twice a day, 6 days a week, such behavior would not be appropriate for a younger athlete, especially given the significant links to overtraining and burnout (Côté \& Hay, 2002). Aspiring musicians, however, may need to commit in a manner similar to that of an elite athlete from early in their development if they are to progress to elite levels of performance. Music, therefore, presents a prime opportunity to examine how PCDEs are used to facilitate development from initiation until elite participation.

An individuals' level of cognitive maturity may also influence how they apply the desired behavior. In the early years, it may be apt for a young performer to follow simple teacher or coach led goals. However, as the performer gets older and gains autonomy over their development (a crucial factor in attaining and maintaining world class performance; Bloom, 1985; Csikszentmihalyi, Rathunde, \& Whalen, 1993), self-driven and self-regulated goal setting behaviors are required. Accordingly, before the potentially substantial benefits of PCDE-based TID processes may be realized, it is important to establish differences (if any) in the set of behaviors required at different points during development and within different performance domains.

Based on these considerations, and building on previous findings (e.g., MacNamara et al., 2010), the purpose of this second retrospective study was to increase our understanding of environmental and chronological influences on the deployment of PCDEs. Specifically, we examined the careers of successful performers, purposefully sampled from contrasting performance domains, to determine:

(a) the PCDEs that facilitated the successful negotiation of the pathway to excellence for this sample, (offering a confirmatory study to support the MacNamara et al.'s investigation), and;

(b) if PCDEs were operationalized differently at different stages and within different domains (i.e., team sport, track and field athletics, music).

\section{Method}

\section{Participants}

Data were collected from a purposeful sample of elite performers $(n=24,12$ female, 12 male; Age $=25-56$ years) who were all performing at an elite level at the time of data collection. Given our contention that PCDEs may be operationalized differentially within different domains, we purposefully sampled elite performers from different environments; namely, track and field athletics $(n=8)$, team sports (hockey and rugby, $n=8)$, and classical music $(n=8)$. These domains were selected on the basis of other parallel projects which suggested a number of significant contrasts between these environments, in terms of both level and timing of challenge (e.g., MacNamara, Holmes, 
\& Collins, 2006, 2008). Following Ericsson and Smith (1991), elite performance was defined as consistently superior performance on a specified set of representative tasks for a domain. For instance, all bar one of the track and field athletes were Olympic, European, or World medalists, and all had consistently reached top 8 finishes at such championships. The team players had all represented their country at senior level on more than 50 occasions and the musicians were all leading professional players with acclaimed orchestras. While the average age of each cohort was different (team sport $=28.5$ years; track and field athletics $=28.9$ years, music $=41.8$ years) each reflected the average age of elite performers in their respective domains. For example, the average age of the top four rugby teams that competed at the 2004 World Cup was between 25.5 and 27.2 years. Similarly the average age of the USA Track and Field team that competed at the World Championships in 2005 was 26.5 years, and a classical musician would not gain a solo position in a leading orchestra before, at least, their early thirties (Bennett, 2008). Accordingly, the participant groups were considered representative of elite performers in each of the disciplines.

\section{Procedure}

Ethical approval was granted from the first author's institutional ethics committee and informed consent was obtained from all participants. The data collection was organized in two phases using a semistructured interview methodology. To ensure an optimum personal context to the data, it was crucial that each participant was able to relate his or her experiences clearly to the key stages that applied to their own careers (cf. Ollis et al., 2006). Accordingly, in the first phase and in collaboration with each participant, a graphic time line of each performer's career was developed (see Figure 1). Guided questioning allowed an exploration of the different stages and transitions encountered along the pathway to excellence. Building on this stage of questioning, the second phase explored the PCDEs used by the participants during the macro and micro stages and transitions identified in the first part of the interview. Each question in the interview guide was intended to be open-ended thus yielding a variety of responses that were pertinent to each performer. Specific probes and prompts were used for clarification and elaboration of key points and to obtain consistency in the depth of responses across participants (Patton, 2002).

\section{Data Analysis}

All interviews were transcribed verbatim. Each interview lasted between 66 and 125 min, supported by introductory and debrief phases, with the majority of interviews lasting $80 \mathrm{~min}$ or longer. The timelines were verified, and data from the interviews were analyzed using the qualitative data analysis program Atlas.ti. An inductive / deductive approach was taken in the analysis of the data. The inductive content analysis of the data followed the recommendations of Côté and colleagues (Côté, Salmela, Baria, \& Russell, 1993) and mirrored those steps reported in MacNamara et al.'s (under review) investigation. The subsequent deductive content analysis involved reanalyzing the results of the inductive content analysis data using the PCDEs from MacNamara et al.'s (under review) investigation as the grouping variable to explore the extent to which the PCDEs reported by the current participants matched those generated in the initial investigation (Marshall \& Rossman, 1995; Patton, 2002). Validity and trustworthiness were ensured using the same steps as reported in MacNamara et al.'s (under review) investigation. 


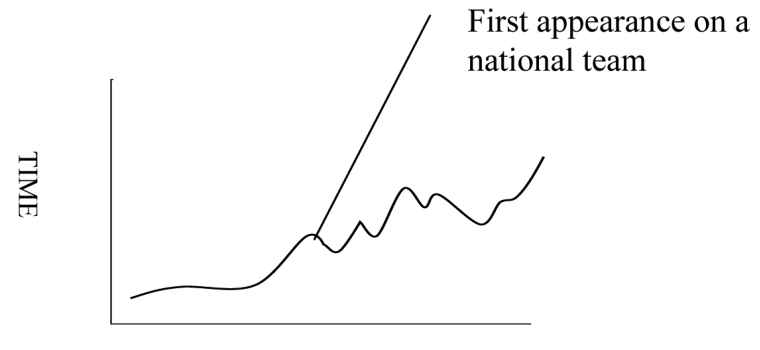

PROGRESSION

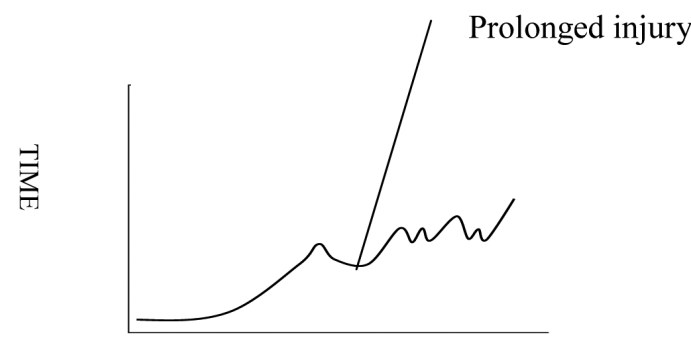

PROGRESSION

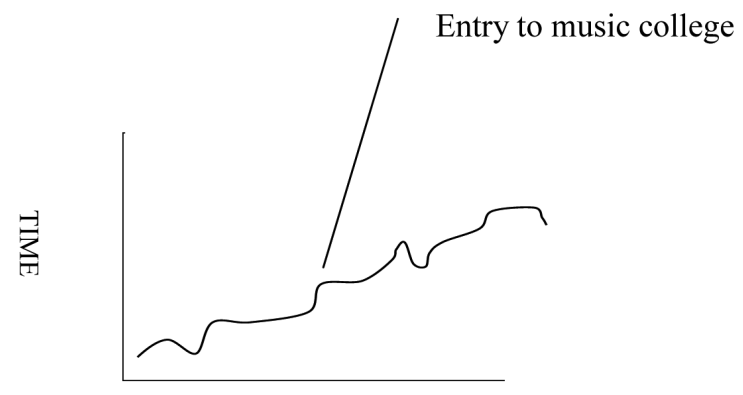

PROGRESSION

Figure 1 - Individual exemplars of the 'pathway to excellence'. (a) Team player's 'Pathway to excellence'. (b) Track and field athlete's 'Pathway to excellence'. (c) Musician's 'Pathway to excellence'.

\section{Results and Discussion}

The results are organized in two sections. The first section describes the PCDEs that facilitated the successful negotiation of the pathway to excellence along with an exploration of how these were employed differentially at different stages and across different performance domains. Quotations are used throughout this section to ensure that the reader gains an appreciation of the context in which the themes 
emerged from the data. For convenience and clarity these themes are italicized in the text. The second section presents the results of the deductive analysis.

\section{PCDEs That Facilitated the Successful Negotiation of the Pathway to Excellence}

Participants were asked to draw diagrams of their personal development in their activities and consider the factors that facilitated the successful negotiation of the stages and transitions along the pathways to excellence (see Table 1). The nonlinear examples shown in Figure 1 are indicative of the pathways offered by the participants. Although all participants broadly followed the generic stages of development outlined by Côté (1999; see Table 1), it was noticeable that each took a different route toward elite status (Stevenson, 1990). The pathways to excellence shown in Figure 1 are dynamic, nonlinear, and individualized with participants describing a series of increasingly challenging events once they committed to their activities. Adding to this complexity were domain related differences in the nature and timing of their commitment (Vaeyens, Lenoir, Williams, $\&$ Philippaerts, 2008). The musicians described relatively more challenges and transitions early in their development compared with their sporting counterparts, reflecting the considerable practice and technical skill acquisition required from an early age in that domain.

I was already putting in quite a lot of practice on the piano and the flute by age 10 at least a couple of hours a day and it was hard but I knew the level of work needed so by the time I was 13 I was spending hours on practice. [Musician]

Given these challenges, it is unsurprising that attitudes and behaviors (see Table 2) facilitative of deliberate practice were associated with the musicians' early participation (Holt \& Dunn, 2004).

I just always wanted to do all the things a little bit better or a little bit harder or faster and I was totally fascinated by it and when I realised that that I was good at it, then I practiced even harder so that I could play all the wonderful things that I would listen to on recordings. [Musician]

In contrast, track and field athletes did not have to invest in similar amounts of coaching or technical practice until later in their development but instead relied on 'natural' talent and physical attributes to succeed during their early participation (cf. Bloom, 1985; Côté, 1999). Reflecting these findings, one track athlete, when asked about the training she did in the lead up to winning the World Junior Championships, commented: "I wasn't even training properly at that stage . . . I was just running!” It wasn't until sport specific systems (e.g., competition, training at senior level) required them to invest considerably in their activity that the track and field athletes started to commit to the pursuit of excellence.

When I finished school I didn't go on to do A levels because it wouldn't allow me to go to warm weather training or go to competitions and I thought 'nope, can't do it!' So that was it, all the decisions I made had to do with running and how I could make myself a better athlete. [Track and Field athlete] 


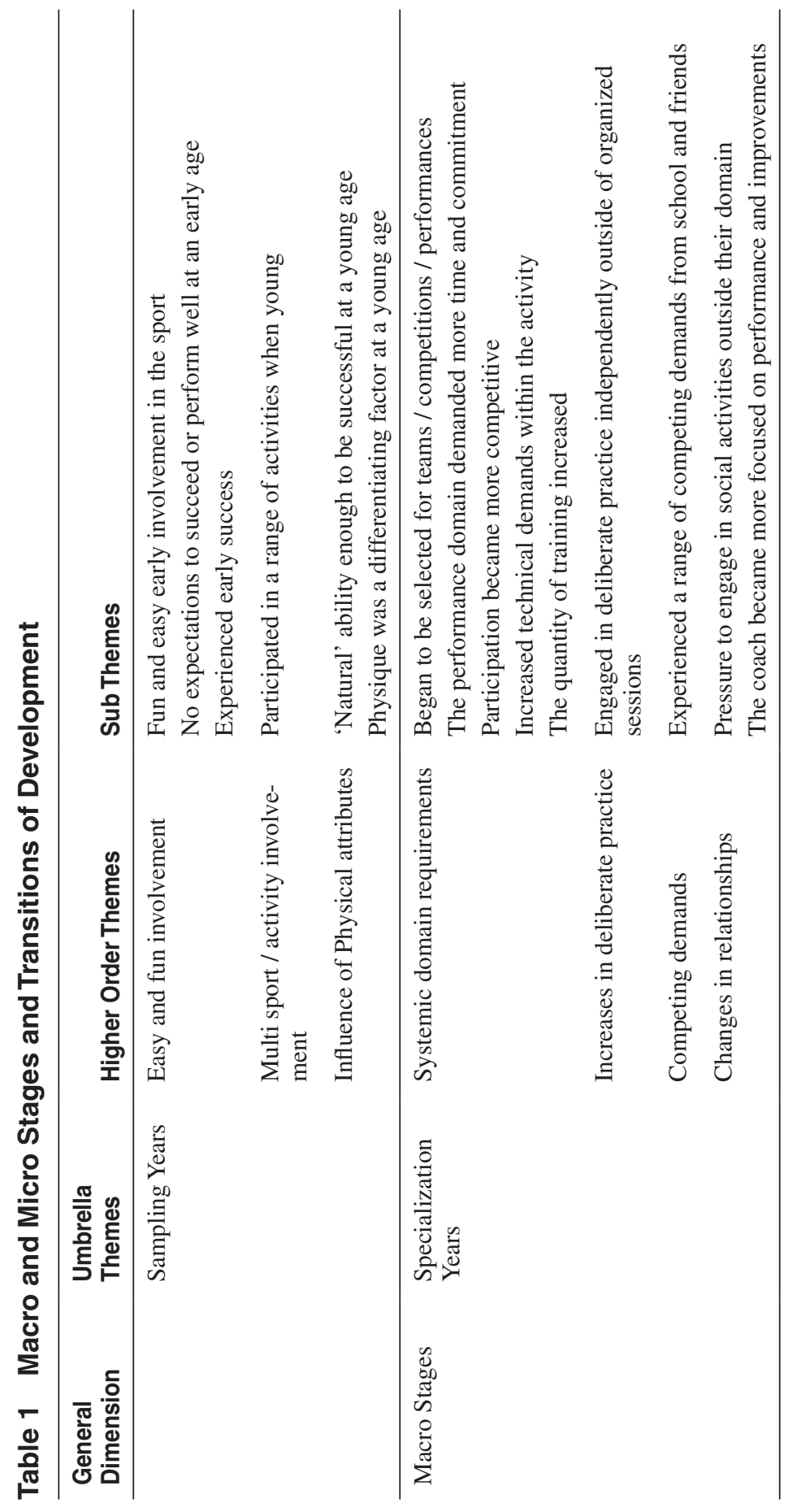




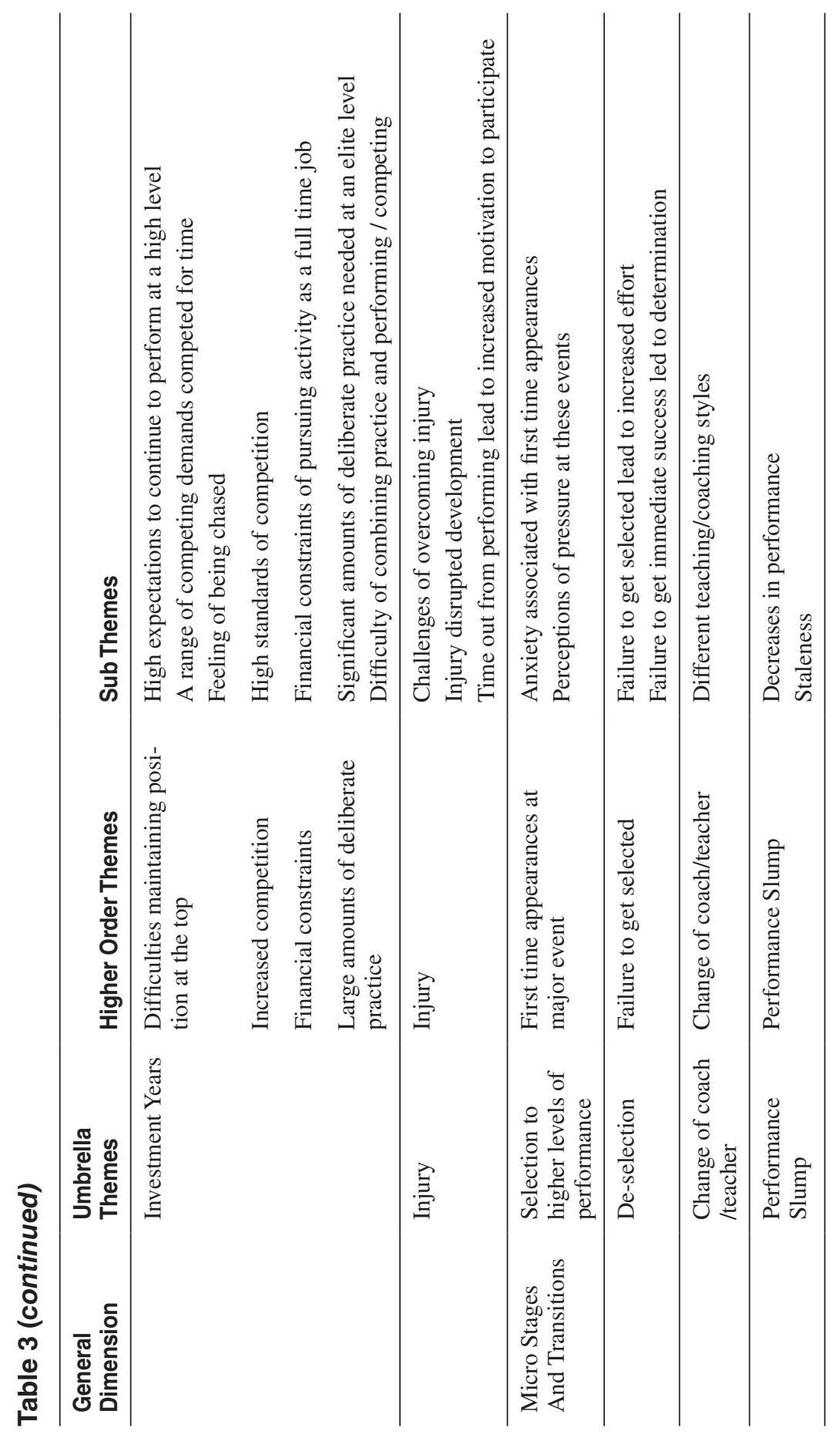




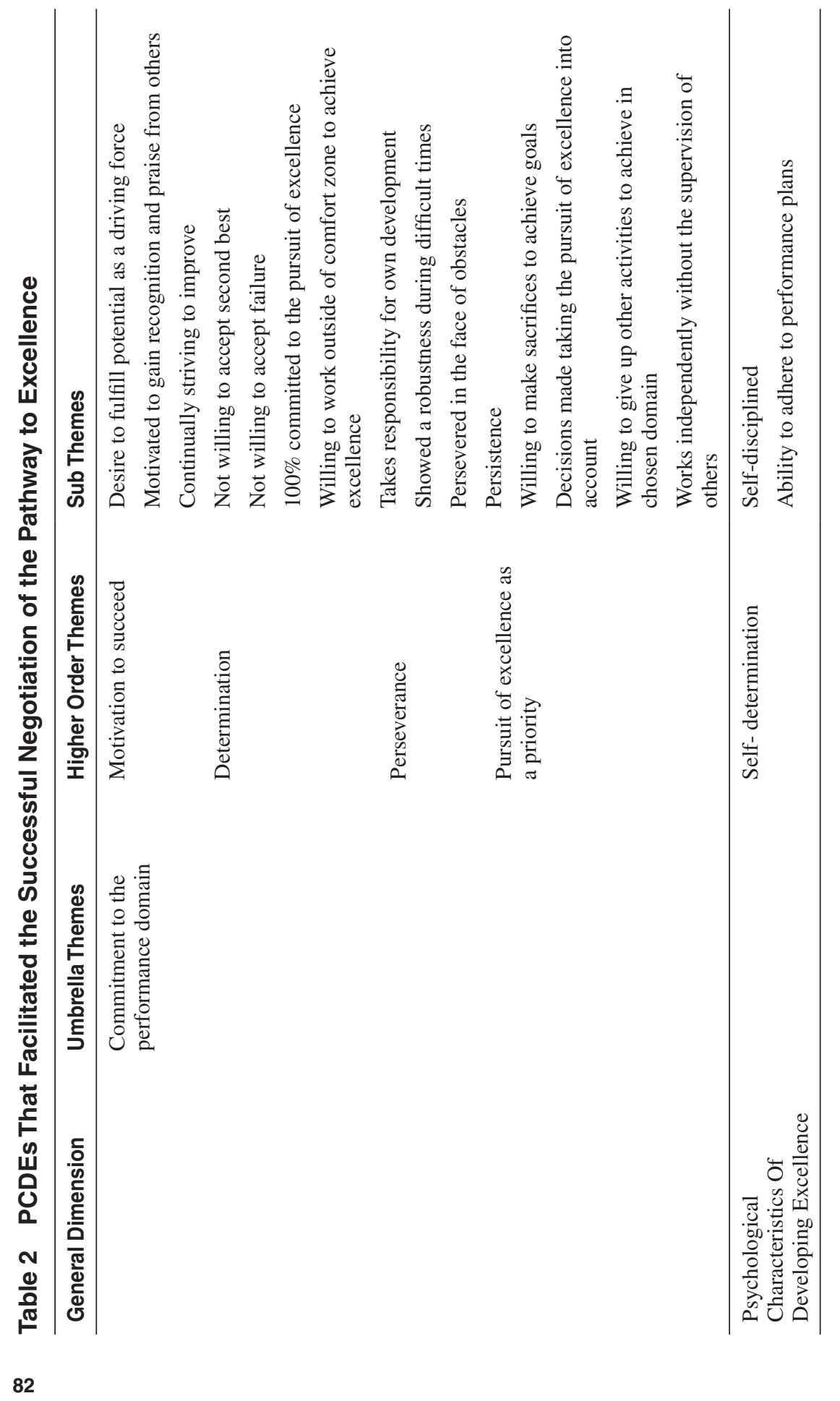




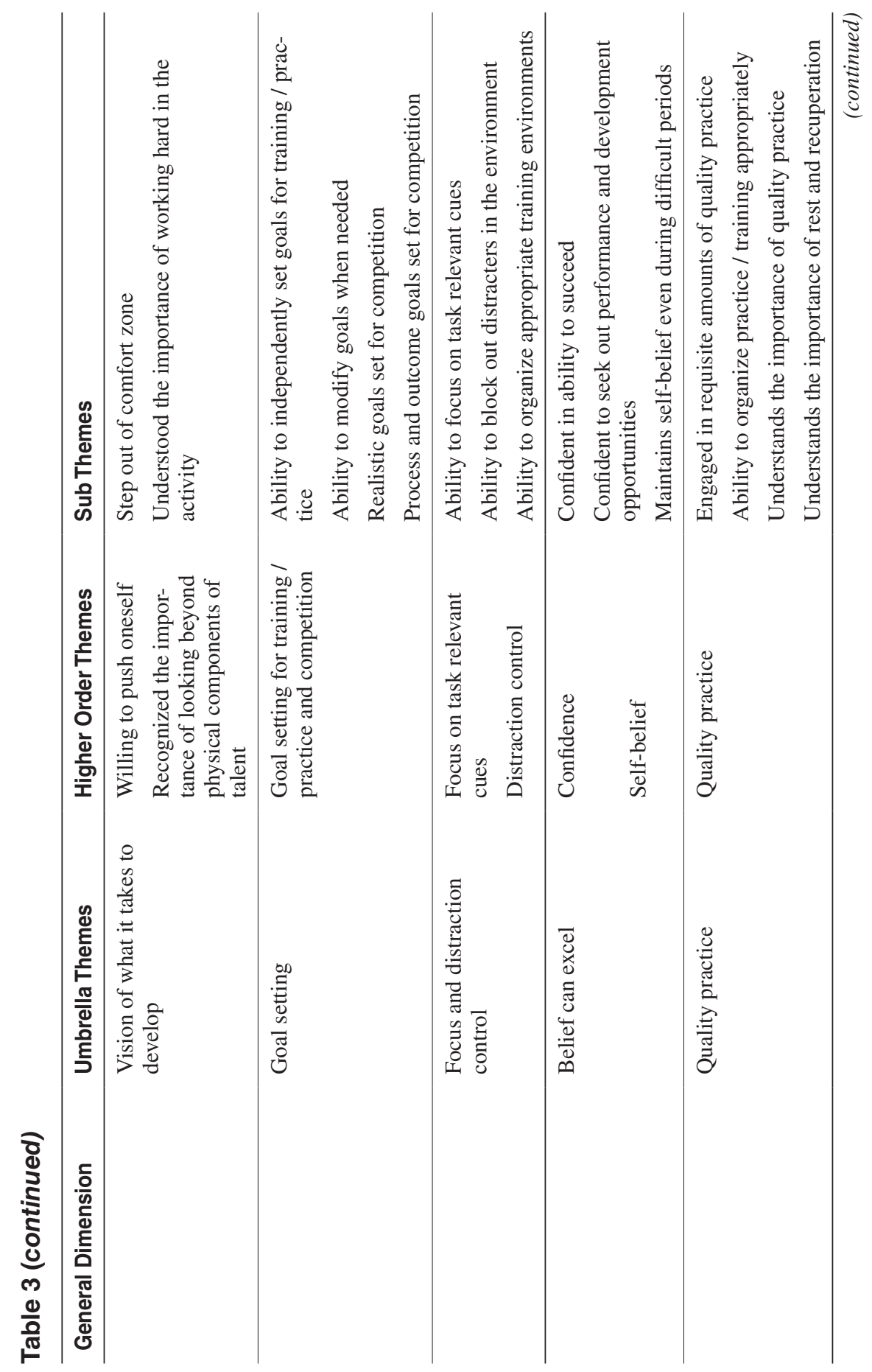




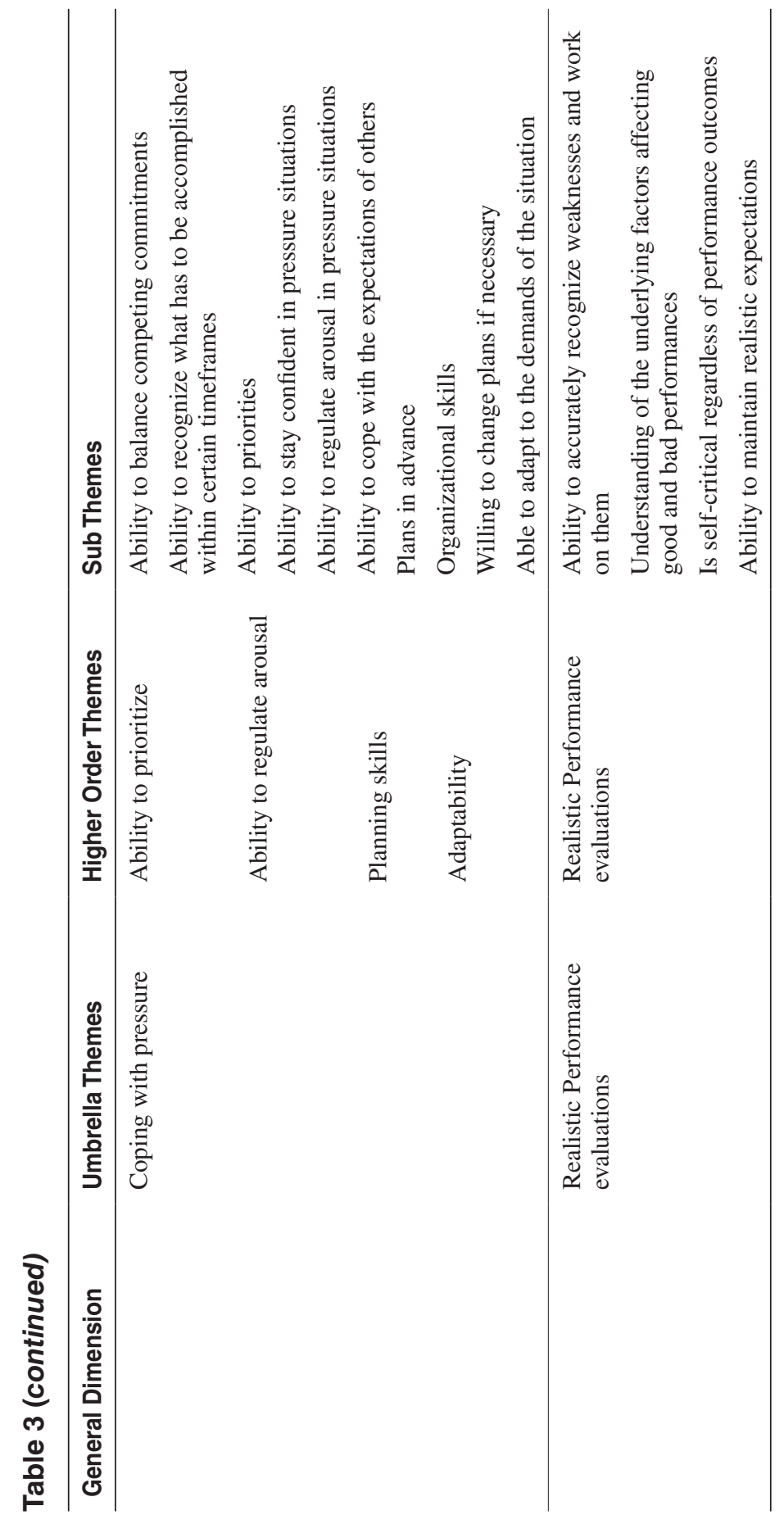




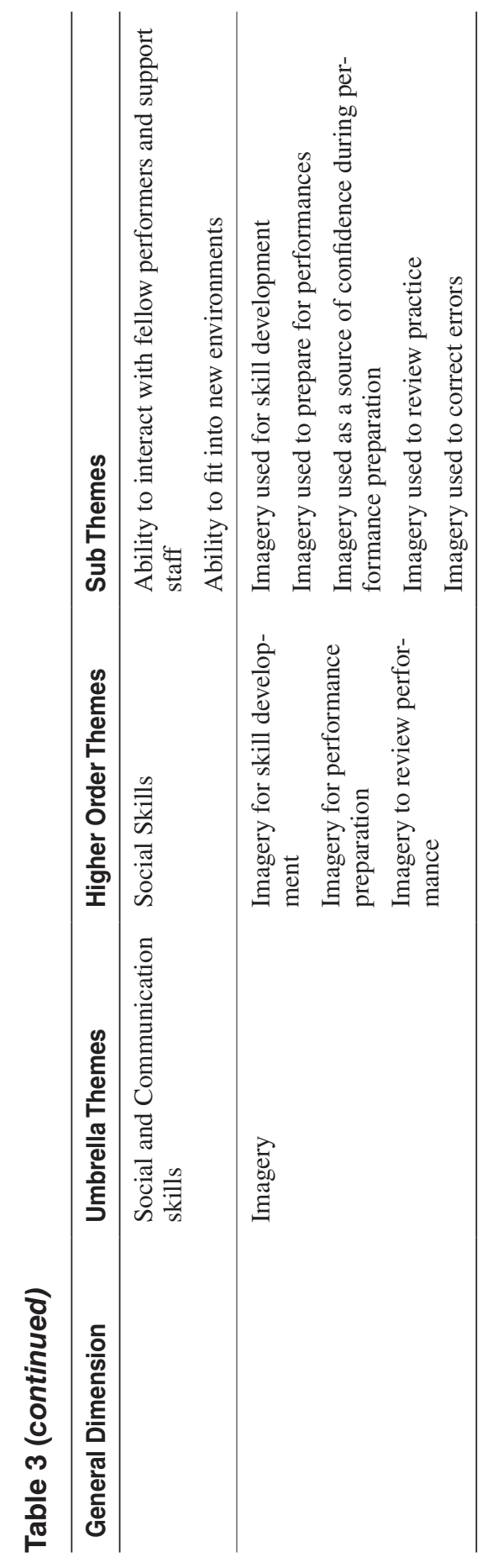


Team sport participants highlighted similar developments noting that they committed to their sport at around 16 years of age, coinciding with selection to representative teams.

It was all fairly easy going when I was young and then when I made the breakthrough to the senior set up it all changed and I had to start to take it much more seriously ... so much more is expected once you make it to that level . . . the standard really rockets and you have to really become dedicated. [Team player]

I suppose once I started to make national teams at around 16 years of age, I noticed that the level of expectations changed... and I suppose that environment soon taught me that there were times that I needed to buckle down and really think about what I was doing ... no one is there to do it for you so you have to do it yourself. [Team Player]

It was interesting that all participants expressed an appreciation that success, especially at high levels of performance, was reliant on more than physical components of talent.

There was a guy called [name] who had talent to burn, and through whatever cause or whatever reason he just didn't want to put the effort in. He just didn't have the application to achieve what he could. There were lots of people around him pushing him but he just didn't have the interest. [Track and Field athlete]

Once 'committed' to the pursuit of excellence (recognizing that this commitment occurred at different times within the different performance contexts), the importance of PCDEs (e.g., goal setting, focus and distraction control, self-belief, engaging in quality practice) as developmental mechanisms was emphasized by all participants.

It was $99.98 \%$ sweat really, there was always the feeling that I could make it, that I could get to the top, I think without that I couldn't have survived, so that self-belief and the sweat and the hard work made the difference. (Musician)

I didn't want to give people an excuse for not playing me again . . . I was determined to give it my best shot and if I still didn't get picked, I still didn't, but I didn't want there to be any excuses so I focused completely on what I had to do to meet those goals, to achieve what I knew I was capable of doing. [Team Player]

You have to have goals, and having short term goals is as important as having long term goals because you have to have short term goals to reach the long term goals don't you? So long term goal is the Olympics but obviously there are other championships before that so they are my goals as well, so it just having something every 6 or 7 weeks to aim for, and then re-evaluating where you are and setting more goals for the next stage and it helps to map out your progress like that. [Track and Field Athlete]

These PCDEs were equally important in helping the participants cope with the distractions that were extraneous to, but nonetheless influenced, their actual performance domain (e.g., peer pressure, social life). A range of coping skills (e.g., 
planning, ability to prioritize, goal-setting) also helped participants to balance competing demands (e.g., education, training / practice) during their school / university and employment years.

Well it was a lot different to when I was younger and all I had to think about was playing. Once I left school, like I said I didn't go to university and had to get a job. All of a sudden I realized that I had to think about things, plan a bit better so that I could fit everything in. [Team Player]

The ability to prioritize their sport or music set them apart from their less successful peers, and placed them at an advantage to those unable to cope with the development pathway and its demands.

Yeah at 17, 18 people start socialising and I wasn't really able to do that because I had to get up in the morning and train. So I thought, I can carry on with rugby and do well, and it was always a mindset that I can always go and do those things later on in my life but I was going to give sport everything while I could. [Team Player]

Participants identified an interestingly common series of micro stages and transitions along the pathway to excellence (e.g., injury, selection, de-selection, change of coach / teacher, performance slumps; see Table 1). Nevertheless, a comparison of the time-lines in Figure 1 reflects domain-related differences in the timings of these events, with the musicians experiencing relatively more 'ups and downs' (interpreted as micro stages and transitions) than their sporting counterparts during their initial participation. In contrast, the sport participants did not describe the same wave-like patterns until they were further along the pathway to excellence. Regardless of these temporal differences, however, the micro stages and transitions experienced by the participants (and, of course, their successful completion) appeared to have significant consequences on future participation.

I was gutted about not getting selected for that tournament but in the end of the day what I really wanted to do was play for [name of country]. I was still young so I knew that if I stuck with it, worked harder that I would be able to challenge for a spot. So I suppose that setback there really made me even more determined to do everything possible to achieve my goals. (Team Player)

I was in great shape ... was ready to really do well and then I got injured so I couldn't compete during that season ... and it is so frustrating but I think that I dealt with it well and worked hard to make sure I got myself in that position again where I could compete and you have got to dig deep and it makes you stronger and as corny as it sounds that is what happened, that motivation made me stronger and made me want to go back and show everyone again what I was capable of. [Track and Field Athlete]

The extent to which these micro stages and transitions were experienced as facilitators or debilitators varied considerably and was dependent on how they were interpreted by the individual. For example, a number of participants experienced significant injuries or set backs during their careers and although these challenges led to a downward transition for some, for others it marked an upward point in their 
development. In short, most successful participants deployed PCDEs to maximize development opportunities and minimize possible disruptions to their development. For example, all the participants highlighted how they used realistic performance evaluations to identify their weaknesses and learn from setbacks (e.g., de-selection; significant losses) encountered during their career:

I was always told as a kid that you couldn't win everything. So I always tried to learn from a defeat as well a win. So when I lost something I would sit down and think why did I lose, what can I do to fix that the next time around, so I would go away and think about it and put it back into my training and then come back again and hopefully do a lot better the next time ... [ Track and Field Athlete]

I make myself think that one defeat is two successes so every time that I got defeated I could go back home and train a bit harder, work out why I got defeated and learn from it, learn from your mistakes more than anything else. [Team Player]

In response to these challenges, participants outlined how confidence, self-belief, and commitment behaviors allowed them to maximize these development opportunities and maintain an upward progression.

It is just sheer determination and not staying knocked when you take a knock and but bouncing back instead. I never let myself stay knocked but always believed in myself and found ways to be even better. [Musician]

I had a huge belief that I was able to do it, that I would become Olympic champion, a huge belief that I could medal, and a huge belief that I could run as quick and quicker as anyone else. I knew that I didn't want to be an athlete that was making up the numbers, so I had this confidence that I belonged in that group ... that I had the ability to compete at that level. [Track and Field Athlete]

Many of the participants noted how an absence of PCDEs limited the ability of 'talented' peers to successfully negotiate key development challenges (e.g., increases in deliberate practice, increased competition).

I played with a guy, [name], when I was young and he was a guy who was really big for his age and he could just barge his way down the pitch. And he was a guy all the way up that everyone knew about, was watching out for and any opposition that you came up against knew and feared him. But I think that as guys got older and bigger they caught up and he didn't stand out as much. And then other guys made the break through at senior level and you could see it was because they really wanted it, worked hard at it and just didn't give up. [Team Player]

Simply, the effective application of PCDEs (e.g., realistic performance evaluations, coping with pressure, confidence) helped the performers adjust to key transitional challenges and interpret them as positive catalysts for change.

You need to be able to deal with the ups and downs because there are a lot of people who struggle with not playing well or when things go badly and unless you can tough out those times you will never succeed. So that is what I did and I came back even stronger from that disappointment. [Musician] 
It was having the determination and the willingness to get up and brush yourself off and go AHHHH, and just go again.... and just take the beating and think 'how do I get faster?' 'What do I need to be able to do to compete at this level?' I know that that when some people lose they just think 'ah ****, I am never going to be good enough, and they just walk away from the sport ... But not me! [Team Player]

I always try to turn the negatives into positives ... I ran in the Commonwealth Games and made the final but then I tore my hamstring . . . I mean I was on the verge of winning. . . . So I could have walked away and thought that I didn't want to do athletics any more because that was a big disappointment but I sat down and I thought that I had got so close and I can do this again which I did. I went out and ran a personal best this year, and I got myself back into a situation where I was ready to perform at the top, mentally, and physically. [Track and Field Athlete]

Once they reached elite levels of performance the participants described how coping skills, such as planning, adaptability, and the ability to prioritize activities allowed them cope and flourish under the significant pressures of their domain.

Once you progress your aspirations always have to rise ... if you don't change you are lost. If you didn't adapt you couldn't stay at this level. On the field you have got to change, make yourself better because the rules change, players are getting better, teams are getting more complicated game plans. [Team Player]

PCDEs were also shown to be important while trying to maintain their positions at the top of their domains and cope with the unique pressures this status entails (Gould et al., 1993). For example, the participants spoke about the need to change their performance environment and independently seek out and adapt to fresh ideas from coaches or teachers.

The game is constantly changing and there is always someone wanting your position and you are going to get caught and passed out by younger guys and fitter guys if you don't adapt your experience . . y your natural ability is only going to bring you so far, so I never got complacent or stayed still but always thought about ways to improve. [Team Player]

I think that if I had stayed in the same place that I was I wouldn't have got any better. I would have kept going downhill, and I would have lost all interest. But moving down here (to a new training group) is like a new start. I am doing things and I am thinking - wow I have never done this before and it is really exciting, and I think that if I keep doing this I wonder what the outcome is going to be, how fast am I going to be able to go? [Track and Field Athlete]

Even though progress was characterized by increases in deliberate practice, the participants clearly enjoyed the challenges of the developmental process. Although deliberate practice has been traditionally conceptualized as an activity that is 'not inherently enjoyable' (Ericsson, 1996), the current findings resonate more with the findings of Starkes et al. (1996) and Helsen et al. (1998) who suggest that athletes are likely to describe highly effortful and relevant forms of practice as enjoyable. 


\section{Differential Deployment of PCDEs: Contextual Differences}

While PCDEs were evident throughout the development pathway, the manner by which they were deployed depended on the characteristics (e.g., cognitive maturation, age) and context (e.g., stage of development, performance domain) of the individual performer. For example, the participants described goal-setting behaviors during the early years that were largely driven by significant others (e.g., parents, coaches, teachers).

At that stage (when you were young) you didn't really have a plan about what you were doing...you just worked towards whatever the teacher set out for you ... did what you were told and I suppose you didn't really question it ... just worked hard to achieve those targets. [Musician]

It was more just going down there to the club and doing what you were told really, what the coaches wanted you to do. At that age you never really questioned what you were doing, you just got on with it and did whatever you were told. [Track and Field Athlete]

As the participants matured they were given more responsibility for their own progress and began to set, monitor and self-reflect on their goals independently.

Once you get older you have to be very self-motivating and set out where you wanted to get to and I used to do that ... once I started getting selected for international teams I knew I just wanted to get better . . . get more of that! So I used to set myself targets ... goals that I wanted to achieve in a training session or for a season, and I used to have a sort of self administered reward and penalty system to get myself together and if things weren't going to plan, I would sit down and think what I had to do differently . . . what else did I need to aim for ... [Team Player]

Similar patterns were also evident in the deployment of other psychological skills. One musician, for instance, noted how he relied on others to plan, supervise, and adjust his practice when he was young.

When I was young, it was easy, there was a lot of input from the teacher there and they really mapped out what I had to do and there was always someone there to listen to what I was playing, tell me what I was doing right or wrong so a teacher supervised practice during all the lunch breaks and after school so I never found it difficult to get practice done because someone was always there to help. [Musician]

However, later in the interview the same musician described how he independently planned appropriate times and environments for practice once he moved into secondary school where the same level of supervision was not available.

You have to be disciplined and just get on with practicing by yourself. It is easy just to practice badly and not learn from it but I always tried to make sure that it was the best practice possible ... that I really listened to what I was playing and made sure that I improved with everything that I did. No one else is going to do it for you so you have to do it for yourself. [Musician] 
These psychological characteristics (i.e., commitment, motivation, determination) were developed and refined throughout development but were especially important as they attempted to make the 'step-up' to elite levels of performance and maintain that position. It is important to note contextual differences in this key transition, with the athletes describing how moving from age-group into senior competition marked the start of this transition

People used to wonder how I was doing so well because they used to beat me when I was younger. Whether it was my hard work or whether their commitment wasn't as strong as mine I don't know. I think I might not have been as talented as others but with hard work and by pushing and pushing, I was able to make it to the top and stay there longer. So I think that I became successful as a senior out of hard work and not just because of talent. [Track and Field Athlete]

On the other hand, the team sport participants noted that getting selected for international teams, rather than age, heralded their transition to elite sport:

I got my chance on the senior team early but I didn't nail down my place so then I did a really hard summer of training, I put in lots of work behind the scenes - weight training, fitness and I think that I was just really committed to improving and getting better and upping my level of performance so I could make it at that level. [Team Player]

A shift in responsibility was evident from 'others' (e.g., parents, teachers, coaches) promoting and reinforcing PCDEs in the early years, toward self initiated and autonomous behaviors in the later years when the performers were given more independence. Although this change in behavior was in part dependent on age, the requirements of the performance environment also seemed to drive the manner by which PCDEs were deployed. It was clear that the musicians had to possess and self-deploy PCDEs from earlier in their development than their sporting counterparts to cope with the challenges (e.g., significant amounts of deliberate practice) that they faced. That is not to say, however, that TID schemes in sport should not encourage the development of PCDEs as early as possible. It may well be that less successful (but more physically gifted) athletes than those sampled in this study did not realize their potential because they lacked the necessary psychological skills, or certainly the abilities to deploy these effectively, to cope with the challenges they faced along the pathway to excellence. In parallel, it may well be that the lack of PCDEs 'kicks in' later for such sports, meaning that an athlete's early success is not realized at senior level. In either case, we suggest there is a compelling case that systematic attention to PCDEs can only benefit the performer. Simply, the manner by which PCDEs are deployed must match the challenges faced by performers at specific points of development.

\section{Results of the Deductive Analysis}

Table 3 highlights the substantial support for the PCDEs found in MacNamara et al.'s study (2010) as facilitative of the successful negotiation of the pathway to excellence for the current participants. Nevertheless, it is also important to note that the addition of different development pathways (i.e., music) resulted in the addition of several new PCDEs. For example, social skills and focus and distraction 


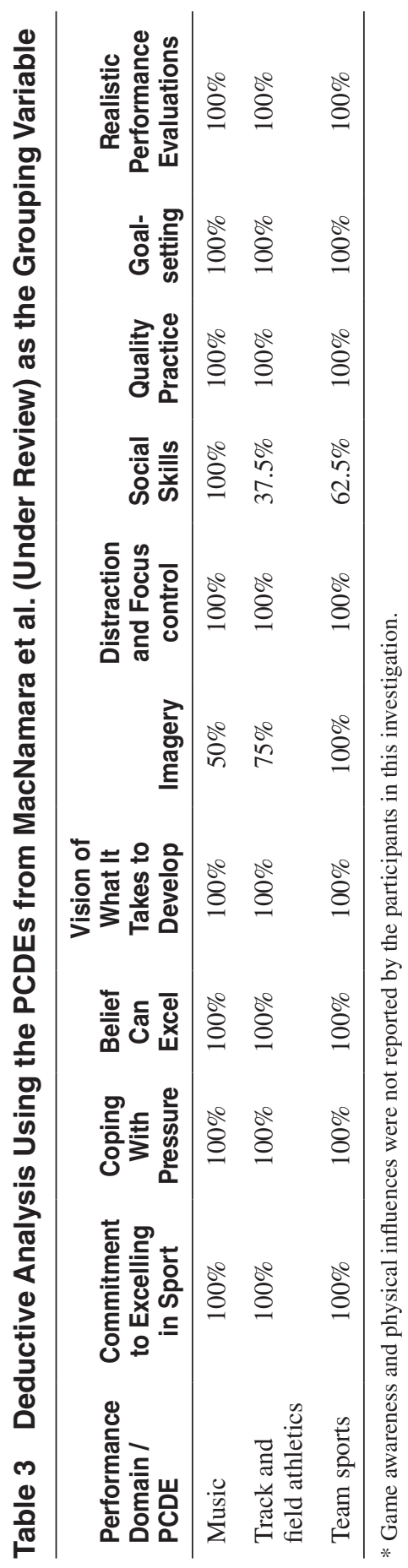


control were not identified in MacNamara et al.'s (2010) earlier study but emerged as important PCDEs in this study. Support for similar characteristics as facilitative of development is available elsewhere in the literature (e.g., Baker \& Horton, 2004). Interestingly, specific PCDEs (e.g., imagery) were predominantly reported by the sport participants reflecting the emphasis placed on these concepts within this particular domain. However, many of the musicians did describe how they engaged in imagery, suggesting that it is indeed a 'characteristic' of excellence as well as being amenable to development through experience and teaching.

\section{General Discussion}

The current results provide confirmatory support for the PCDEs that emerged in from MacNamara et al.'s investigation, as well as a number of additional items as key determinants and mechanisms of development (see Table 3 ). A key finding concerned the differential deployment of PCDEs relative to the individual's age, focus, stage of development/level of maturation, and performance domain. For example, there appears to be a shift in responsibility from 'others' (e.g., parents, teachers, coaches) promoting and reinforcing PCDEs in the early years toward self initiated and autonomous behaviors in the later years. Essentially the differential deployment of PCDEs can be understood from a self-regulation perspective (Karoly, 1993). Self-regulated learners have the skills to self-monitor their progress, manage their emotions, focus on self-improvement, and seek help and support from others when necessary (Petlichkoff, 2004). Conversely, performers without these skills do not take personal responsibility for their own development but instead rely on others and attribute failures to maladaptive reasons. Both these standpoints find interesting partial resonance in the ideas of Dweck's 'Growth mindset' (Dweck, 2008). Research has repeatedly shown that a growth mindset fosters positive attitudes toward practice and learning, leads to a hunger for feedback, and a greater ability to deal with setbacks (Dweck, 2008). Critically, given the demands of high-level participation in any domain, a self-regulated athlete who possesses a growth mindset also has the ability to initiate and persist at tasks that are not inherently motivating or interesting, though none the less important for development. This ability to effectively cope with the stressors of development and adapt to the challenges faced, specifically increased autonomy and responsibility over one's development, is a key component of successful development (Côté, 1999). If these challenges can be anticipated and the necessary skills checked and developed in advance, the pathway to excellence can be considerably smoothed and the individual prepared for future developments. In short, it may be that PCDEs represent the ways in which constructs such as the growth mindset are realized. If so, explicit development is to be strongly recommended.

Since the goal of talent development (TD) is to provide the most appropriate learning environment to realize an individual's potential to excel, it is surprising that these crucial determinants of development are consistently overlooked (Vaeyens et al., 2008). Few TD models systematically encourage the development of selfregulated learners, despite the support for the benefits of developing self-regulation skills available in the literature (Gould \& Chung, 2004; Zimmerman, 2000; Zimmerman \& Kitsantis, 1997). Ceci and colleagues (Ceci, Barnett, \& Kanaya, 2003) offered support for this argument by suggesting that experts may not have any 'hardware' advantages but instead their motivation to take advantage of development 
opportunities leads to the commitment necessary to achieve expert performance. This line of research has important implications for applied practices in TID. Instead of the traditional focus on environmental (e.g., early specialization, enrichment programs), physical, and/or anthropometric factors, TID models should consider, monitor, and develop all the components that underpin the capacity to develop. To this end, Dweck (2008) suggested that growth mindsets can be induced with messages from the environment that talent can be developed over time with effort ( $c f$. Diamond, Barnett, Thomas, \& Munro, 2007). From an applied perspective, the complexity of skills needed to meet these requirements supports the implementation of individualized and flexible approaches to TD that meet the specific requirements of the performer. By recognizing the multiple factors that influence development, the efficiency of TID models is increased by neither excluding 'potential' through inappropriate early identification measures, nor ignoring crucial talent development variables that contribute toward the fulfillment of potential.

\section{Limitations and Future Research}

It has to be admitted that there are some limitations to the retrospective research paradigm heretofore most evident within the TID literature (e.g., self-report bias, truthfulness, reliability; Coolican, 2004). Therefore, to strengthen our understanding of the role of PCDEs in facilitating talent development, and to overcome these methodological limitations, longitudinal research is needed. Starkes, Helsen, and Jack (2001) have recommended that longitudinal and field based research should form the basis of future research in both talent development and expertise. In line with these recommendations, a longitudinal study is currently underway tracking the development of young performers from different domains by monitoring micro and macro-level transitions during development, and the extent to which PCDEs are employed and considered during these transitional phases.

\section{References}

Abbott, A., Collins, D., \& Sowerby, K. (2007). Developing the potential of young people in sport. Edinburgh: sportscotland.

Abbott, A., Button, C., Pepping, G-J., \& Collins, D. (2005). Unnatural selection: Talent identification and development in sport. Nonlinear Dynamics Psychology and Life Sciences, 9, 61-88.

Baker, J., \& Horton, S. (2004). A review of primary and secondary influences on sport expertise. High Ability Studies, 15, 211-228.

Bennett, D. (2008). Understanding the classical music profession: The past, the present and strategies for the future. Oxon, UK: Ashgate.

Bloom, B.S. (1985). Developing talent in young people. New York: Ballantine.

Ceci, S.J., Barnett, S.M., \& Kanaya, T. (2003). Developing childhood proclivities into adult competencies: The overlooked multiplier effect. In R.J. Sternberg \& E.L. Grigorenko (Eds.), The psychology of abilities, competencies, and expertise (pp. 126-158). Cambridge, England: Cambridge University Press.

Coolican, H. (2004). Research methods and statistics in psychology. London: Hodder \& Stoughton.

Côté, J., \& Hay, J. (2002). Children's involvement in sport: A developmental perspective. In J.M. Silva \& D.E. Stevens (Eds.), Psychological foundations of sport (pp. 484-502). Boston: Allyn \& Bacon. 
Côté, J. (1999). The influence of the family in the development of talent in sports. The Sport Psychologist, 13, 395-417.

Côté, J., Salmela, J.H., Baria, A., \& Russell, S.J. (1993). Organizing and interpreting unstructured qualitative data. The Sport Psychologist, 6, 55-64.

Csikszentmihalyi, M., Rathunde, K., \& Whalen, S. (1993). Talented teenagers: The roots of success and failure. New York: Cambridge University Press.

Diamond, A., Barnett, W., Thomas, J., \& Munro, S. (2007). Preschool program improves cognitive control. Science, 318, 1387-1388.

Dweck, C. (2008). Mindset: The New Psychology of Success. New York: Random House.

Ericsson, K.A. (1996). The road to expert performance: Empirical evidence from the arts and sciences, sports, and games. Mahwah, $\mathrm{NJ}$ : Erlbaum.

Ericsson, K.A., \& Smith, J. (1991). Prospects and limits in the empirical study of expertise: An introduction. In K.A. Ericsson \& J. Smith (Eds.), Toward a general theory of expertise: Prospects and limits (pp. 1-38). Cambridge: Cambridge University Press.

Gould, D., \& Chung, Y. (2004). Self-regulation in young, middle and older adulthood. In M.R. Weiss (Ed.), Developmental sport psychology and exercise psychology: A lifespan perspective (pp. 383-402). Morganton, WV: Fitness Information Technology.

Gould, D., Diffenbach, K., \& Moffett, A. (2002). Psychological characteristics and their development in Olympic champions. Journal of Applied Sport Psychology, 14, 172-204.

Gould, D., Jackson, S., \& Finch, L. (1993). Sources of stress in national champion figure skaters. Journal of Sport \& Exercise Psychology, 15, 134-159.

Holt, N.L., \& Dunn, J.G.H. (2004). Toward a grounded theory of the psychosocial competencies and environmental conditions associated with soccer success. Journal of Applied Sport Psychology, 16, 199-219.

Karoly, P. (1993). Mechanisms of self-regulation: a systems view. Annual Review of Psychology, 44, 23-52.

MacNamara, A., Button, A., \& Collins, D. (under review).The role of psychological characteristics in facilitating the pathway to elite performance. Part 1: Identifying mental skills and behaviours. The Sport Psychologist.

MacNamara, A., Holmes, P., \& Collins, D. (2006). The Pathway to excellence: The role of psychological characteristics in negotiating the challenges of musical development. British Journal of Music Education, 23, 80-98.

MacNamara, A., Holmes, P., \& Collins, D. (2008). Negotiating transitions in musical development: The role of psychological characteristics of developing excellence. Psychology of Music, 36, 335-352.

Marshall, C., \& Rossman, G. (1995). Designing qualitative research (2nd ed.). Newbury Park: Sage.

Ollis, S., MacPherson, A., \& Collins, D. (2006). Expertise and talent development in rugby referees: An ethnographic enquiry. Journal of Sports Sciences, 24, 309-322.

Orlick, T., \& Partington, J. (1998). Mental links to excellence. The Sport Psychologist, 2, $105-130$.

Patton, M.Q. (2002). Qualitative research and evaluation methods. Newbury Park, CA: Sage.

Petlichkoff, L.M. (2004). Self-regulation skills in children and adolescents. In M.R. Weiss (Ed.), Developmental sport and exercise psychology: A lifespan perspective (pp. 273-292). Morgantown, WV: Fitness Information Technology.

Simonton, D.K. (1999). Talent and its development: An emergenic and epigenetic model. Psychological Review, 106, 435-457.

Starkes, J.L., Deakin, J., Allard, F., Hodges, N.J., \& Hayes, A. (1996). Deliberate practice in sports: What is it anyway? In K.A. Ericsson (Ed.), The road to excellence: The acquisition of expert performance in the arts and sciences, sports, and games (pp. 81-106). Mahwah, NJ: Erlbaum.

Starkes, J.L., Helsen, W., \& Jack, R. (2001). Expert performance in sport and dance. In R.N. Singer, H.A. Hausenblas, \& C.M. Janelle (Eds.), Handbook of Sport Psychology (pp. 174-201). New York: Wiley. 
Stevenson, C.L. (1990). The Early Careers of International Athletes. Sociology of Sport Journal, 7, 238-253.

Vaeyens, R., Lenoir, M., Williams, A.M., \& Philippaerts, R.M. (2008). Talent identification and development programmes in sport: Current models and future directions. Sports Medicine (Auckland, N.Z.), 38, 703-714.

Williams, J.M., \& Krane, V. (2001). Psychological characteristics of peak performance. In J.M. Williams (Ed.), Applied sport psychology: Personal growth to peak performance. Mountain View, CA: Mayfield.

Zimmerman, B.J. (2000). Attaining self-regulation: A social cognitive perspective. In M. Boekaerts, P.R. Pintrich, \& M. Zeidner (Eds.), Handbook of self-regulation (pp. 13-39). San Diego: Academic Press.

Zimmerman, B.J., \& Kitsantas, A. (1997). Developmental phases in self-regulation: Shifting from process goals to outcome goals. Journal of Educational Psychology, 89, 29-36. 